\title{
Vacuna anti-rotavirus segura y efectiva para prevenir diarreas severas en niños
}

\author{
Vaccine against rotavirus is safe and effective to prevent severe gastroenteritis in children \\ Ruiz-Palacios G. N Engl J Med 2006; 354(1):11-22
}

\section{Objetivo}

Determinar la efectividad de una vacuna a virus humanos vivos atenuados en la prevención de la gastroenteritis aguda severa (GAES) por rotavirus en menores de un año y su seguridad en cuanto a la invaginación intestinal.

\section{Diseño}

Ensayo clínico aleatorizado, doble ciego, controlado contra placebo.

\section{Lugar}

Once países de Latinoamérica y Finlandia (2003-2005).

\section{Pacientes}

63225 niños sanos de 6-13 semanas de vida reclutados en Centros de Salud u Hospitales Públicos.

\section{Intervención}

Se los aleatorizó a recibir dos dosis de vacuna oral (Rotarix®) o placebo separados por uno a dos meses. Recibieron además el resto de las inmunizaciones de los programas locales, aunque la vacuna Sabin se administró con una separación de al menos dos semanas.

\section{Medición de resultados principales}

Riesgo de desarrollar invaginación intestinal al mes de cada dosis. Prevención de casos de GEAS por rotavirus entre las dos semanas siguientes a la administración de la segunda dosis y el año de vida del niño; hospitalizaciones y diarrea con deshidratación moderada a severa.

El análisis de seguridad fue por intención de tratar* pero el de eficacia fue según protocolo* $\mathrm{e}$ incluyó sólo a los que recibieron dos dosis ( $89 \%$ del total) que, según los autores, no difierieron del resto.

\section{Resultados Principales \\ Ver tabla 1.}

\section{Tabla 1: Resultados de Eficacia y Seguridad}

\begin{tabular}{|c|c|c|c|c|c|}
\hline \multicolumn{2}{|c|}{$\begin{array}{l}\text { Niños con al menos } \\
\text { un evento }\end{array}$} & $\begin{array}{l}\text { Vacuna } \\
n=9009\end{array}$ & $\begin{array}{l}\begin{array}{l}\text { Placebo } \\
n=8858\end{array} \\
\end{array}$ & RRR (IC95\%) & NNT (IC95\%) \\
\hline \multicolumn{2}{|c|}{ Diarrea severa por rotavirus } & 12 & 77 & $84,7 \% \quad(71,9-91,7)$ & $136(106-189)$ \\
\hline \multirow{2}{*}{$\begin{array}{l}\text { Hospitalización } \\
\text { por diarrea }\end{array}$} & por rotavirus & 9 & 59 & $85(69,8-92,6)$ & $177(134-260)$ \\
\hline & de otra causa & 145 & 246 & $42 \%(29,0-52,7)$ & $86(63-136)$ \\
\hline \multicolumn{2}{|c|}{ Invaginación intestinal } & 6 & 7 & $15,7 \%(-150,7-+71,7)$ & - \\
\hline \multicolumn{2}{|l|}{ Muerte } & 56 & 43 & $-28,0 \% \quad(-90,3-13,9)$ & - \\
\hline
\end{tabular}

\section{Conclusiones}

La vacuna anti-rotavirus a virus humanos vivos atenuados es segura y efectiva para prevenir diarreas severas.

Palabras clave: rotavirus, vacuna, diarrea, infante, efectos adversos. Key words: rotavirus vaccination, diarrea, child, adverse effects. Fuente de financiamiento: GlaxoSmithKline Biologicals.

\section{Comentario}

La infección por rotavirus es la principal causa de GEAS en los niños en todo el mundo. En Argentina se la estima responsable del $20 \%$ de las internaciones por diarrea (hasta $50 \%$ en el invierno) $71 \%$ de las cuales corresponden a menores de un año, variando la mortalidad y tasa de internación en función de la accesibilidad al sistema de salud².

Hacia los tres años de edad casi todos los niños han estado en contacto con el virus y aunque la inmunidad mucosa no es completamente eficaz para prevenir nuevas infecciones, luego de un episodio alcanza el $77 \%$ y luego de una o dos infecciones, la inmunidad natural confiere una protección contra episodios severos del 87 al $100 \%$ respectivamente.

Luego del retiro del mercado de la vacuna anti-rotavirus rhesus debido a su posible asociación con mayor riesgo de invaginación intestinal, hubo múltiples reportes de la efectividad de las cepas atenuadas del virus humano ${ }^{3}$ en la prevención de las infecciones severas y de la hospitalización; sin embargo quedaba aún por aclarar su perfil de seguridad.
Es probable que los resultados de esta investigación sobreestimen el efecto beneficioso de la vacuna, principalmente en niños de mala situación socioeconómica, nutricional y de accesibilidad al sistema de salud; ya que sólo incluyó niños sanos y no desnutridos. Este grupo es el de mayor riesgo de desarrollar complicaciones y su capacidad para desarrollar una respuesta inmune eficaz podría estar comprometida. Además, la implementación de hidratación precoz podría alterar la estimación de la magnitud de la eficacia de la vacuna, cuestiones que podrían aclararse mediante estudios pragmáticos*.

\section{Conclusiones del comentador}

Se confirma la eficacia y la falta de asociación entre la inmunización y la invaginación intestinal, crucial para la implementación masiva de la inmunización.

Chaves SC. Vacuna anti-rotavirus segura y efectiva para prevenir diarreas severas en niños. Evid. actual. práct. ambul; $10(2)$ : 37 , mar-abr.2007. Ruiz-Palacios G, Pérez-Schael I, Velásquez R. Safety and efficacy of an attenuated vaccine against severe Rotavirus gastroenteritis. N Engl J Med 2006; 354(1):11-22. PMID: 16394298. Texto completo disponible en http://content.nejm.org/cgi/reprint/354/1/11.pdf

\section{Referencia}

1. Kane et al. The epidemiology of rotavirus diarrhea in Latin America: anticipating rotavirus vaccines. Rev Panam Salud Publica 2004; 16:371-7.

2. Chaves S. ¿Es eficaz la vacuación contra rotavirus en la prevención de diarreas severas en niños? Evid. actual. pract. ambul. Mar-Abril 2006;9(2):54-5.

3. Vesikari T et al. Safety and Efficacy of a Pentavalent Human-Bovine (WC3) Reassortant Rotavirus Vaccine. N Engl J Med 2006; 354:23-33. 